\title{
Negação, intersubjetividade e polifonia: estudo de caso em processos civis
}

\author{
Negation, intersubjectivity and poliphony: a case study in Civil Proceedings
}

\author{
Ana Lúcia Tinoco Cabral
}

Universidade Cruzeiro do Sul - Brasil

$\diamond$

\begin{abstract}
Resumo: $\mathrm{O}$ artigo apresenta um estudo de caso relativo ao emprego da negação observando como essa estratégia linguística se enquadra no discurso dos profissionais que atuam na área jurídica, marcado pela intersubjetividade e pela polifonia. $\mathrm{O}$ quadro teórico que dá suporte às análises insere-se na linha teórica da Semântica Argumentativa (DUCROT, 1981; 1984) em confluência com os teóricos dedicados aos estudos da Linguística da Enunciação (BENVENISTE, 1966 e 1974; Kerbrat-Orecchioni, 1986 e [1998] 1997) e dos Estudos Gramaticais (MATEUS et al. [1898] 1994; PERES, 2013). O trabalho apresenta alguns conceitos relativos à interação nos Processos Civis, aborda o estatuto da refutação nesse quadro interativo; trata sucintamente do quadro teórico da polifonia que dá suporte às análises assim como os conceitos relativos à negação; e analisa exemplos de enunciados negativos extraídos de um Processo Civil, evidenciando seu caráter polifônico que corrobora a intersubjetividade do discurso dos autos.

Palavras-chave: Negação; Polifonia; Argumentação; Intersubjetividade; Processo Civil
\end{abstract}

\begin{abstract}
This article presents a case study on the use of negation in Civil Proceedings by observing how this linguistic strategy falls within the Legal discourse, outlined by intersubjectivity and poliphony. The theoretical framework that gives support to the analyses is grounded on the Argumentative Semantics (DUCROT, 1981; 1984) in confluence with researchers dedicated to studying the Enunciation Linguistics (BENVENISTE, 1966 and 1974; KERBRAT-ORECCHIONI, 1986 and [1998] 1997) as well as Grammatical Studies (MATEUS et al. [1898] 1994; PERES, 2013). The research presents concepts with regard to the interaction in Civil Proceedings, deals with the refutation statute within this interactive scenario, briefly discusses the poliphony theoretical framework which supports the analyses as well as concepts related to negation, and it also examines some examples on negative wordings drawn from a Civil Proceeding; thus highlighting its poliphonic feature that reinforces intersubjectivity on the case-file discourse.
\end{abstract}

Keywords: Negation; Poliphony; Argument; Intersubjectivity; Civil Proceeding

As disputas judiciais constituem um espaço privilegiado para a argumentação, uma vez que nelas encontram-se dois pontos de vista antagônicos versando sobre o mesmo fato. Temos dedicado nossos estudos ao uso da linguagem verbal pelos profissionais da área jurídica, especialmente, à construção da argumentação em interações por escrito entre advogados, e também à produção científica de estudiosos do Direito (CABRAL, 2007; 2011 e 2014). Relativamente às interações entre advogados, focalizamos estratégias linguísticas utilizadas na prática de advogados para, de um lado, apoiar o próprio discurso, e, de outro, refutar o discurso da parte contrária.
Observamos as estratégias argumentativas utilizadas pelos locutores, marcando tanto a aproximação relativamente ao próprio discurso como o distanciamento em relação ao conteúdo do discurso da parte contrária, caso em que a negação ocupa lugar de destaque. Nessa perspectiva, no presente texto, apresentamos breves análises de empregos da negação com o objetivo de observar como essa estratégia linguística se enquadra no discurso dos profissionais que atuam na área jurídica, marcado pela intersubjetividade e pela polifonia. O quadro teórico que dá suporte às análises insere-se na linha teórica da Semântica Argumentativa (DUCROT, 1980; 1981; 1984) 
em confluência com os teóricos dedicados aos estudos da Linguística da Enunciação (BENVENISTE, 1966 e 1974; KERBRAT-ORECCHIONI, [1998] 1997) e dos Estudos Gramaticais (MATEUS et al. [1898] 1994; PERES, 2013). Como metodologia de análise, seguimos a proposta de Kerbrat-Orecchioni ([1998] 1997): procedemos ao levantamento das marcas linguísticas, neste caso, as formas negativas, procurando observar a intenção que motivou suas escolhas e verificar sua importância para as práticas discursivas dos profissionais da área do Direito. Para dar conta de nossos objetivos, este trabalho apresenta quatro partes, a saber: a primeira apresenta brevemente o quadro característico da prática jurídica de litígio destacando o princípio do contraditório que une as partes envolvidas nessa interação e ressaltando seu caráter intersubjetivo; a segunda aborda aspectos relativos à situação de confronto própria dos litígios, seu estatuto perante a argumentação e seu aspecto polifônico; a terceira discorre sobre negação e polifonia, conceitos que dão suporte a nossas análises; a quarta traz as análises.

\section{Interação e intersubjetividade nos Processos Civis}

É função da regular a atividade dos cidadãos e os órgãos públicos; seu escopo abrange a conservação dos sujeitos jurídicos e sua organização política, além dos bens próprios a esses sujeitos, regulando a atribuição desses bens. Na convivência social, embora os sujeitos procurem manter a paz, conflitos de interesses acontecem com frequência. Tendo em vista que o Estado não permite aos indivíduos fazerem justiça pela própria força a fim de fazer valer sua vontade, os cidadãos têm o direito de invocá-lo para fazer valer a lei para atender aos seus interesses, suas pretensões, para usar o termo jurídico: é o direito de ação, que se concretiza no Processo Civil. Podemos assim afirmar, com Santos (1977), que objetivo do Processo é solucionar conflitos de interesses regulados por lei. Embora a finalidade dos processos judiciais civis seja a composição da paz jurídica (cf. SANTOS, 1977), não se pode ignorar que, em seu cerne, está o confronto. $\mathrm{O}$ processo surge de um confronto e é o confronto que marca a relação entre as partes do processo. Inclusive, entre os princípios que regem a relação entre as partes, encontra-se o princípio do contraditório, determinando que as duas partes têm objetivos que se contradizem (cf. SANTOS, 1977).

Cabral (2007) assevera que o Processo Civil constitui uma sequência interativa de atos provocada por um conflito de interesses entre dois sujeitos, duas partes, a saber: autor e réu. As partes são os sujeitos parciais do processo: o autor age pedindo a prestação jurisdicional do Estado contra o réu, que resiste. A atividade das partes é, por conseguinte, fundamental para o desenvolvimento do processo; ela se liga ao conceito de ônus processual, conceito que, conforme ensina Greco Filho (1996, p. 13), diz respeito à oportunidade de agir e ao direito de agir. Assim, por exemplo, o réu tem o ônus de contestar, de recorrer, etc. A esse respeito, o jurista observa que a omissão da parte pode ter efeitos no processo, uma vez que o processo precisa prosseguir e não pode ficar paralisado pela omissão de qualquer das partes. Em decorrência dessa necessidade, entende-se, na relação jurídica, que a parte que se omite diante de um ônus aceita, inevitavelmente, a consequência legal a ele relacionada. Isso quer dizer que, conforme destacado por Cabral (2007), todas as afirmações do autor que não forem refutadas pelo réu são admitidas como verdadeiras, daí a importância da refutação na contestação, pois o réu não mais poderá negar aquilo que já admitiu como verdadeiro. A negação, na contestação, é, portanto, a resposta de uma das partes ao dizer da outra e, nesse sentido, institui o caráter intersubjetivo do discurso dos autos.

No processo, os locutores não podem perder de vista os demais locutores, especialmente porque os objetivos diferem frente a cada um deles: as partes têm ambas perante o juiz o objetivo de convencê-lo de suas razões e têm entre si, o objetivo de contradizer uma à outra. Apenas o juiz deve exercer suas atividades com imparcialidade, às partes cabe serem parciais (cf. CABRAL, 2007). Essa dinâmica de ter sempre presente a enunciação do outro para construir a sua nos coloca diante do inevitável caráter intersubjetivo e polifônico das interações dos autos; com efeito, encontra-se aí a ideia básica de que "tout acte de parole implique normalement, non seulement une allocution, mais une interlocution (un échange de propos)" (KERBRAT-ORECCHIONI, [1990] 1998, p. 14). É nessa mesma direção que Anscombre e Ducrot afirmam que

l'emploi d'une phrase est um phénomène interindividuel, en événement dans l'histoire des relations entre plusieurs individus: le locuteur l'emploie parce que la situation où il se trouve face aux personnes qui l'entourent (destinataires et auditeurs) l'amène, ou au moins l'autorise, à le faire; et s'il l'emploie, c'est d'autre part qu'il cherche, grâce à elle, à produire un certain effet sur ceux à qui ou pour qui il parle. (ANSCOMBRE e DUCROT, 1997, p. 16)

Essa afirmação nos permite compreender que nem sempre a interação verbal implica solidariedade entre os interlocutores; na medida em que eles são parceiros do jogo da linguagem, a interação implica necessariamente também certa disputa. 


\section{Sobre a ideia de controvérsia e polifonia}

Meyer (2008, p. 21), ao apresentar sua definição de Retórica, afirma que "la rhétorique est la négociation de la distance entre des individus à propos d'une question donnée". Essa definição nos coloca diante de uma expectativa de acordo ligada ao processo argumentativo também destacado por Amossy (2014, p. 19), segundo quem a retórica "pose la nécessité de trouver, à travers l'échange verbal, une réponse commune qui permette de dépasser les différends". A autora pondera, no entanto, que uma ideia utópica de relações perfeitas repousaria sobre a possibilidade de acordo perfeito entre as pessoas sobre as maneiras de encarar, de julgar e de fazer as coisas.

Com efeito, conforme lembra Amossy (2014), a retórica se debruça sobre as condições necessárias para a obtenção de um acordo; concordamos com a autora de que a ideia de acordo mantém uma posição privilegiada nas teorias que tratam da argumentação, embora haja alguns autores que se dediquem à polêmica e ao desacordo. Meyer (2008) mesmo admite que nem sempre se busca diminuir a distância, e cita o exemplo dos insultos. Entretanto, vale retomar novamente uma afirmação de Amossy (2014, p. 29), "le conflit appelle une résolution", o que, no Processo Civil, cabe apenas ao juiz.

Relativamente ao processo argumentativo específico dos Processos Civis, a ideia de busca de acordo como inerente à argumentação apresenta um problema no que concerne à relação entre as partes: buscam as partes uma negociação, a redução de uma distância? Estará o acordo entre os objetivos das partes nos processo?

Podemos afirmar, com Cabral (2007), que o acordo que cada uma das partes busca não é com a outra, mas com um terceiro interlocutor, o juiz, instância que representa o sistema de leis que, por sua vez, cristaliza o modo de ver da sociedade, posição que cada uma das partes procura identificar como sendo alinhada à sua problemática.

No Processo Civil, encontramos uma situação específica baseada no princípio do contraditório que rege a relação entre as partes; trata-se também de uma situação com características próprias, regida por convenções particulares, configurando o que Dascal (2008) define como uma situação de controvérsia, isto é, uma situação na qual existe um conflito persistente de pontos de vista, em que, muitas vezes a diferença parece ser difícil de se resolver, conforme lembra Amossy (2014). No Processo Civil, cabe ao juiz impor uma resolução, o que não quer dizer que ambas as partes estarão de acordo com ela; aliás, ao contrário, conforme a instância do processo, é inclusive possível à parte recorrer da decisão judicial, apelando para uma instância superior a fim de buscar um julgamento a seu favor.
Mas, para além da ideia de controvérsia básica própria de uma relação de desacordo, é preciso pensar também em situações em que a exposição da distância entre dois sujeitos consiste no argumento perante um terceiro para ganhar a adesão deste. Nessa perspectiva, Cabral (2007) destaca que o réu nega as afirmações do autor, e este nega o dizer daquele, ambos visando a ganhar a adesão do juiz, a quem é atribuído o poder de promover a solução, por meio da sentença. Considerando que o poder de decisão se encontra nas mãos do juiz, é com ele que cada uma das partes busca o acordo, é a ele que elas pretendem convencer, evidenciando um distanciamento relativamente à parte contrária.

Nesse contexto, a negação parece ocupar um papel importante, especialmente, para marcar a diferença. A interação nos autos do Processo Civil, no que diz respeito às partes especialmente, fundamenta-se num discurso cujo objetivo é refutar os argumentos da parte contrária, marcando a diferença de pontos de vista; podemos assim afirmar que o discurso dos autos é essencialmente polifônico. Com efeito, atuam no Processo dois sujeitos intencionais que mobilizam vozes e pontos de vista contraditórios para agir sobre um terceiro. As duas partes, conforme já mostrado por Cabral (2007), se confrontam, uma nega as afirmações da outra; autor e réu sustentam discursos antagônicos, evidenciando uma oposição entre eles.

É importante observar que, nessa interação conflituosa, o pronunciamento do réu, na Contestação, baseia-se nas afirmações do autor, que devem ser refutadas sob pena de serem admitidas como procedentes, caso não sejam negadas. A partir da Inicial, posta pelo autor, as enunciações de cada uma das partes toma, portanto, como ponto de partida, a enunciação da parte contrária, funda-se nela e assume uma posição perante ela, no caso específico, fundamentalmente de desacordo, de distância, daí a importância da negação, de que trataremos a seguir.

\section{Negação, polifonia e intersubjetividade}

Do ponto de vista gramatical, Segundo Mateus et al. ([1989] 1994, p. 110), "a negação é uma operação de modificação que atua sobre os vários tipos de modalidades - lexicalizadas, proposicionais, ilocutórias e pragmáticas - contrariando-as ou contradizendo-as." Ela pode se manifestar explicita ou implicitamente, como em enunciados que não apresentam elementos formais de negação, mas funcionam com sentido negativo relativamente ao contexto, como, por exemplo, em frases interrogativas ou mesmo afirmativas que "no processo específico de interacção são interpretadas como negativas" (MATEUS et al. [1989] 1994, p. 110). Enunciados no futuro que têm forma interrogativa podem, 
por exemplo, ter um valor pragmático que não é o de uma pergunta, mas da expressão da dúvida do locutor. $\mathrm{Na}$ mesma direção, o recurso a perguntas como forma de negação implícita é uma estratégia definida por Mateus et al. ([1989] 1994) como um ato ilocutório indireto utilizado pelo locutor com o intuito de obter de seu interlocutor uma ratificação de uma avaliação expressa por ele, locutor. Ainda com relação à interrogação como forma de negação, Anscombre e Ducrot (1997) admitem que negação e interrogação possuem ambas a mesma orientação argumentativa, embora a interrogação seja mais fraca que a negação.

Dúvida do locutor remete a uma outra enunciação efetiva ou possível e põe, para além da problemática de um outro ponto de vista, configurando um valor polifônico, a questão a intersubjetividade constitutiva do ato de enunciação: "la condition d'intersubjectivité permet seule la communication linguistique (BENVENISTE, 1974, p. 77). A negação põe necessariamente uma voz que vai de encontro a outra que a antecede, marcando uma posição contrária, e também evidenciando a intersubjetividade constitutiva do processo de enunciação.

A manifestação explícita da negação se dá por meio dos advérbios não, nunca e jamais, em posição préverbal. Outros advérbios e expressões adverbiais, como por exemplo, raramente, poucas vezes, dificilmente são responsáveis pela negação de forma implícita e podem apresentar valores qualitativos e quantitativos que reduzem as propriedades relativas aos estados de coisas descritos pelas respectivas proposições. A negação expressa-se também por meio de prefixos de negação ou de unidades lexicais que têm valor de negação com relação a outras unidades lexicais; ela pode ainda ser intensificada, fato que, segundo Mateus et al. ([1989] 1994, p. 114), pode ter como objetivo a "explicitação quer das intenções do locutor quer da posição deste em relação aos estados de coisas que refere”. Explicitação de intenções diz respeito à argumentação, e também à expressão de um ponto de vista, ambas atitudes do locutor que necessariamente volta-se para um interlocutor.

Acrescentamos, com Negroni e Colado (2001, p. 204), que, entre enunciados afirmativos e negativos há uma grande dissimetria, visto que "la afirmación está presente en la negación de una manera más fundamental de lo que la negación lo está en la afirmación". Nosso corpus corrobora essa postura teórica importante: as afirmações de uma parte devem ser negadas pela outra, do que decorre que, aquelas negações trazem no seu bojo afirmações que possam tê-las provocado, mesmo que as afirmações que lhes deram origem não estejam explicitadas. No mesmo sentido, Ducrot (1981) relata que os filósofos da linguagem da "escola de Oxford" consideram as enunciações negativas como um ato de fala particular, como uma modalidade de julgamento, tendo em vista que uma enunciação negativa geralmente se emprega como opondo-se a uma afirmação que a antecedeu.

Partindo da noção de negação de frase e negação de constituinte proposta pelos transformacionalistas, Ducrot $(1981$, p. 98, 99) apresenta dois tipos de negação:

uma negação 'polêmica', que corresponde a um ato de fala de negação, e que se apresenta, pois, como refutação de um enunciado positivo correspondente (trata-se sempre, nesse caso, de uma negação de frase). E, por outro lado, uma negação 'descritiva', que é a afirmação de um conteúdo negativo, sem referência a uma afirmação antitética. (DUCROT, 1981, p. 98)

A negação polêmica constitui um ato de negação em que se refuta um conteúdo positivo, sendo, conforme ensina Ducrot (1981, p. 95), "uma modalidade de julgamento", tendo como função "dar uma informação contraditória à da frase positiva sem permitir necessariamente concluir pela informação contrária" (DUCROT, 1981, p. 95). Trata-se, como explicam Negroni e Callado (2001), de opor o ponto de vista de dois enunciadores antagônicos postos em cena pelo locutor.

Com a negação descritiva, negação do constituinte, dá-se uma informação que é do tipo negativo, ou seja, é a afirmação de um conteúdo negativo. Há ainda outro tipo de negação, a negação metalinguística, que, conforme ensinado por Negroni e Callado (2001, p. 209), caracteriza-se por "descalificar el marco e espacio de discurso impuesto por una palabra anterior del interlocutor o del proprio locutor". Conforme destacam essas autoras, não se trata aí de se oporem dois enunciadores, como no caso da negação polêmica postulada por Ducrot, mas "dos locutores distintos o un mismo locutor en momentos diferentes" (NEGRONI \& CALLADO, 2001, p. 209). Vai no mesmo sentido a afirmação de Givón (1993) de que o locutor, quando usa uma negação, não está comunicando uma informação nova ao interlocutor; ele está, na realidade, corrigindo as crenças erradas do seu interlocutor. Inclusive, pelo seu caráter de discordância, em algumas sociedades muito tradicionais e fechadas, a negação direta é tida como uma manifestação rude e é evitada. A respeito da negação metalinguística, Peres (2013, p. 465) assevera que ela serve também para "relativizar a verdade de uma afirmação prévia".

Ducrot (1984) associa a negação polêmica à polifonia, uma vez que esse tipo de negação prevê enunciadores distintos cujos pontos de vista são diferentes. Nos autos, encontram-se em oposição dois locutores que tentam ganhar a adesão de um terceiro. Cada deles apela para a refutação do dizer do outro como estratégia para convencer esse terceiro. Entretanto, nem sempre o dizer 
do outro está efetivamente presente no autos; a parte é muitas vezes impelida a prever o ponto de vista da parte contrária para negá-lo; desta perspectiva, a negação no discurso de cada uma das partes faz alusão a um ponto de vista atribuído por conjectura lógica à parte contrária. Podemos assim afirmar que ora o discurso da parte faz referência a um interlocutor, quando de fato retoma o dizer da parte contrária, ora apresenta o ponto de vista de um enunciador o qual assimila à parte contrária. Em ambos os casos, a negação constitui ocorrência de polifonia, pois há outro ponto de vista que se inscreve no discurso da parte em pronunciamento.

No que diz respeito ao conceito de polifonia, especificamente, da qual a negação constitui uma marca importante, vale ressaltar as observações de Amossy (2005, p. 68), para quem "elle permet dès lors au discours visant à agir sur l'autre une orchestration plus ou moins savante à ses propres fins d'efficacité". Concordamos com a autora ao afirmar que a polifonia, constituindo uma estratégia preciosa para a argumentação, "articule tout naturellement non seulement sur l'argumentation dans la langue, mais aussi sur l'argumentation dans le discours" (AMOSSY, 2005, p. 68).

Apesar de ocorrer também na Inicial, a presença da negação é muito mais expressiva nas demais partes do processo, Contestação e Réplica; afinal, em um conflito de interesses é previsível que o réu procure negar as acusações que lhe faz o autor da ação, ou seu ponto de vista, e vice versa, pois, de acordo com o princípio básico do Processo Civil, todas as afirmações de uma parte que não forem negadas pela parte contrária serão tidas como assumidamente verdadeiras. Daí a importância de a parte antecipar-se, trazendo para a sua enunciação o ponto de vista de um enunciador ao qual se oponha, marcando a diferença. Podemos, com base no contexto posto pelo processo, afirmar que nos Processos Civis, a negação representa fundamentalmente a refutação de um enunciado positivo dito ou possível de ser afirmado, evidenciando uma tomada de posição da parte relativamente ao ponto de vista da parte contrária. Essa é a situação de enunciação imposta pelos autos, fundamentalmente polêmica e intersubjetiva.

\section{Alguns casos de negação nas interações processuais}

Para as análises, a título de exemplificação, elegemos um processo, isto é, uma Ação Ordinária de Cobrança que correu na quarta cível (central) de São Paulo, processo n. 1754/94, do qual foram extraídos os excertos analisados. A Autora da ação é uma empresa que atua no ramo de engenharia eletrônica e a Ré, uma empresa fabricante de relógios de precisão. A Autora desenvolveu um aparelho para imprimir informações em cartão de ponto e vendeu essa tecnologia à Ré. Por meio de um contrato, ficou pactuado entre as partes um pagamento mínimo dividido em sete parcelas semestrais. Para a garantia desses pagamentos, foram emitidas notas promissórias. Sob alegação de que o projeto é industrialmente inviável, a Ré pagou cinco das sete parcelas e interrompeu os pagamentos. A ação é para cobrar as parcelas que não foram pagas. Conforme previsto pelo sistema processual, após a propositura da ação pela Autora com a Inicial, por meio da qual se pede ao juiz que determine a cobrança, cabe à Ré responder, por meio da Contestação.

$\mathrm{O}$ conjunto de enunciados analisados constitui-se basicamente de excertos extraídos da Contestação e, portanto a manifestações da Ré; dois excertos apenas correspondem à enunciação da Autora. Sendo assim, após a apresentação de cada excerto, indicamos entre parênteses a página do processo e a parte a cujo pronunciamento corresponde o excerto.

Considerando que o foco principal de nossas análises constituem enunciações presentes na Contestação, vale iniciar as análises observando a palavra contestação e o verbo contestar, dois vocábulos que fazem parte do vocabulário dos processos. A contestação constitui um dos atos do processo, é o ato de resposta do réu; é, nas palavras de Guimarães (s/d, p. 210), "o meio de defesa, com razões fundamentadas, de que se socorre o réu para negar ou refutar a pretensão do autor e ilidir a ação". Ela pressupõe, conforme já exposto anteriormente neste trabalho, atos de negação, uma vez que tudo aquilo que o Autor afirma, e o Réu não contesta, é tido como fato assumido por este último.

A Contestação é a primeira resposta do réu a acusações feitas pelo Autor; a enunciação desse ato jurídico funda-se assim na enunciação do outro, ao qual se contrapõe, concretizando o que Benveniste (1966) nomeou a intersubjetividade constitutiva da enunciação, "duas figuras necessárias ao quadro figurativo da enunciação, uma na fonte outra no alvo" (CABRAL, 2011, p. 111).

Podemos observar, no enunciado a seguir (1), a palavra contestação e, um pouco mais adiante no mesmo excerto, a palavra improcedência, esta última reforçando o valor negativo intrínseco de contestação.

(1) Assim posto, deve a presente contestação ser acolhida, para o fim de ser decretada a improcedência da ação, com a extinção do processo com o julgamento do mérito e a condenação da A. nas verbas de sucumbência. (PROC. 1754/94:13 - Ré)

Ao nomear o ato jurídico a que faz referência, a Ré explicita seu ponto de vista de oposição à outra parte. 
Trata-se de uma postura essencialmente polifônica, no sentido de que a parte que detém a palavra opõe seu ponto de vista ao da outra parte procurando corrigir perante o juiz os equívocos na enunciação da outra. A contestação põe em evidência dois pontos de vista ligados a dois sujeitos distintos, Autor e Réu, e expõe a adesão do Réu a um ponto de vista que se opõe a Autor. Essa oposição deve fazer-se clara, no entanto, por meio de negações explícitas, que permitem ao locutor deixar inequívoco um posicionamento de oposição relativamente a uma afirmação da parte contrária. Não apenas a uma afirmação propriamente dita, mas também a possíveis discursos ligados a pontos de vista alinhados à parte contrária. Conforme expusemos já neste trabalho, na prática do litígio, a parte muitas vezes precisa antecipar-se ao dizer da parte contrária, prevendo um possível discurso desta que deve ser negado, sob pena de ser admitido como verdadeiro. Nesse sentido, vemos na palavra contestação e no termo improcedência, uma alusão a um enunciador ao qual se assimila à Autora, cujo ponto de vista pode ser inferido pela negação da Ré, configurando a ocorrência intrínseca de polifonia na enunciação dos autos.

Com relação às marcas da negação especificamente, conforme destacamos anteriormente, Mateus et al. $(1898,1994)$ postulam que os elementos de explicitação da negação são os advérbios não, nunca e jamais, em posição pré-verbal. O emprego desses tradicionais advérbios de negação faz, no entanto, parte das expectativas de qualquer usuário da língua e, portanto, não provoca grandes impactos no interlocutor. Quando o locutor tem intenção de surpreender o seu interlocutor, para provocar nele alguma reação, ou quando quer deixá-lo com menores possibilidades de desacordo, o emprego de outras expressões de valor negativo em substituição aos negativos clássicos parece ser um estratégia bastante eficaz. Os exemplos que elencamos a seguir, em (2) e (3), todos extraídos da Contestação, ilustram essa estratégia:

(2) Nenhuma das inovações em questão surtiu resultado. (PROC. 1754/94:10 - Ré)

(3) Sequer a disponibilização dos técnicos da A., na qualidade de cedente da tecnologia, totalizou as 100 (cem) horas (...) (PROC. 1754/94:8 - Ré)

Nos dois exemplos, temos negações categóricas empregadas pela Ré com o intuito de desqualificar as ações da Autora, reforçadas, ainda, pela topicalização de elementos de valor negativo em ambos os excertos: nenhuma e sequer. Cumpre destacar que, na Inicial, a Autora não mencionou nem inovações nem disponibilização de técnicos, ações previstas no contrato previamente assinado pelas partes. Podemos afirmar, com base na enunciação da Ré, que esta, ao recorrer à negação, põe em cena um enunciador que se assimila à Autora, trazendo uma afirmação possível, cujo conteúdo é contemplado pelo contrato, mas cuja explicitação não se encontra realizada efetivamente na Inicial.

Cumpre ainda observar que, nos autos, embora a parte tenha como parâmetro para sua enunciação o dizer da parte contrária, seu interlocutor é o juiz; é a ele que as partes pretendem convencer e, portanto, a quem dirigem sua argumentação; sendo assim, a parte contrária constitui um interlocutor indireto cujo discurso interessa refutar (cf. CABRAL, 2007). Nesse sentido, a Ré contempla uma possiblidade de enunciação da Autora, ao trazer um enunciador a cujo ponto de vista se opõe, e apresenta o discurso contraditório a ela, como se desejasse corrigir um discurso possível de seu interlocutor indireto, para fazer com que o juiz, seu interlocutor direto, adira ao conteúdo de sua enunciação.

Outra forma negativa, os prefixos de negação explicitam o valor negativo de uma asserção e podem ser empregados como uma forma atenuada de negar um conteúdo:

(4) Logo na montagem dos protótipos foi constatada a existência de desenhos com dimensões incorretas. (PROC. 1754/94:9 - Ré)

Incorreta significa aquilo que não está correto, mas pode ser interpretado como algo que também não está totalmente errado, dando margem à dúvida. Em contrapartida, o emprego da palavra errada, cujo significado tem valor negativo mais claro em relação a correta, poderia ser interpretado como contundente e pouco polido, ferindo os princípios de cordialidade previstos pelos código de ética profissional (cf. NEGRÃO, 1988). De fato, incorreta denota uma reticência por parte da Ré em relação ao conteúdo negativo de seu enunciado; a expressão da adesão do locutor ao conteúdo negativo de um enunciado por meio de um prefixo tem, portanto, muito a ver com a significação da palavra escolhida e com a intensidade de negação que o prefixo confere à palavra, uma vez que ele pode ora negar totalmente, ora deixar uma brecha para uma negação apenas parcial.

Cabe observar o caráter descritivo da negação em (4); o emprego do verbo constatar ao qual se liga o complemento desenhos com dimensões incorretas conduz a essa classificação da negação. Não se pode, no entanto, deixar de destacar que, neste caso, a negação descritiva serve à controvérsia, ao embate, na medida em que avalia negativamente uma ação da Autora, servindo à argumentação da Ré em favor de seu ponto de vista.

Embora em muitos casos os prefixos negativos possam ser empregados como uma forma atenuada de 
negar um conteúdo, em outros eles permitem também denotar de forma mais incisiva a adesão do locutor ao conteúdo negativo:

(5) Além do grave problema técnico exposto, ainda subsistente e que por si inviabiliza a produção, foi ainda a Ré obrigada a alterar, projetar, (...) (PROC. 1754/94: 11 - Ré)

(6) Mencionadas modificações fizeram com que o custo do aparelho, conforme apresentado pela A., aumentasse acentuadamente a ponto de tornar impraticável sua comercialização (...) (PROC. 1754/94:11/12 - Ré)

Nos exemplos (5) e (6), o prefixo in/im, como elemento de explicitação da negação, não deixa margem para uma interpretação atenuada; não há possibilidade de in ser interpretado como quase não nos enunciados acima; ao contrário, a leitura que se faz é de que temos absolutamente não. Inviabilizar significa tornar inviável, nega totalmente a possibilidade de viabilização. Como as coisas são viáveis ou não, não havendo meio termo entre viável e não viável, o verbo que nega a viabilização denota a negação absoluta. Assim também ocorre com o adjetivo impraticável. O dicionário (HOUAISS, 2001, p. 1583) traz, como sinônimos para o verbete impraticável as palavras impossível e irrealizável. Impraticável nega, portanto, qualquer possibilidade de realização. Mais uma vez, cabe destacar que, por razões evidentes, a Autora não mencionou, na Inicial, se o projeto era viável nem se a comercialização do produto a ser desenvolvido seria praticável ou não. A Ré opõe-se assim a um enunciador que ela traz ao seu discurso e que assume o projeto como viável e o produto como comercializável; tal enunciador assimila-se a Autora.

Algumas unidades lexicais têm, em relação a outras, sentido negativo e seu emprego em um enunciado explicita a intenção de negar por parte do locutor. O exemplo a seguir (7) ilustra esse tipo de negação:

(7) O sr. Nome Sobrenome, sócio da A. a quem competia essa missão, simplesmente ausentou-se repentinamente do país, em meio ao processo de transferência (que se deparava então com graves dificuldades técnicas), suprimindo com a sua mudança de residência para o exterior os meios pelos quais se exercia a transmissão da tecnologia (PROC. 1754/94:12 - Ré)

Ao verbete suprimir, o dicionário (Houaiss, 2001: 2644) atribui a significação eliminar, extinguir, cancelar. Só se elimina algo que existia previamente; suprimir traz, em sua significação, a negação dessa existência. Suprimir põe a não existência e pressupõe uma exis- tência anterior, cuja extinção é atribuída à parte contrária pela Ré; admite-se assim a existência de uma ação prevista no contrato e efetuada em parte pela Autora e que foi por ela mesma suprimida, o que representa uma negação da própria ação desta, argumento em favor da Ré. Ao mencionar um ato previsto em contrato, a Ré traz para os autos um enunciador que assimila à relação jurídica contratual, que determina os direitos e obrigações de cada uma das partes. Seu discurso apoia-se, portanto, nesse enunciador para criticar as atitudes da Autora.

Observando as ocorrências de negação no corpus, constatamos que o traço pragmaticamente mais eficaz é representado pela presença de uma segunda marca de negação no enunciado, que intensifica a negação, reforçando a adesão de locutor a esse conteúdo. São intensificadores da negação os pronomes indefinidos nenhum, nada e ninguém, que têm valor negativo, e qualquer e algum, que, ocorrendo no enunciado simultaneamente a um advérbio de negação, reforçam o valor negativo do advérbio:

(8) (...) os direitos da concepção industrial por ela cedidos não são de nenhuma serventia, porquanto padece dita concepção industrial de falhas e defeitos de suma gravidade, que afastam o requisito da industriabilidade, vale dizer - não constitui objeto passível de aproveitamento industrial, seja sob o aspecto eminentemente técnico, seja sob o aspecto da viabilidade econômica. (PROC. 1754/94:12 - Ré)

Em (8), o pronome indefinido nenhuma não é essencial à negação, uma vez que ela se explicita pelo uso do advérbio não. Entretanto, seu emprego intensifica a negação e esse reforço funciona como uma estratégia argumentativa a favor do conteúdo enunciado, assumindo o locutor uma posição antagônica à de seu opositor, a quem acusa de ceder direitos que não são de nenhuma serventia. Encontra-se nesse enunciado a alusão a um ponto de vista da parte contrária segundo o qual os direitos por ela cedidos servem à Ré, que por eles deveria, portanto, ter pagado. Aliás, a mesma estratégia utiliza a Autora, em dois momentos: em sua Réplica, fazendo referência à Contestação e, finalmente, no Memorial, em que retoma toda a argumentação da Ré no desenrolar dos atos do processo:

(9) Na contestação apresentada, a ré não alegou qualquer das matérias enumeradas no art. 301 do CPC. (PROC. 1754/94:14 - Autora)

(10) Enfim, a ré não comprovou nenhum fato extintivo do direito da autora. (PROC. 1754/94:51 - Autora) 
As negativas da Autora, tanto em (9) como em (10), fazem alusão à anunciação da Ré, julgando-a pela negação. A Autora parece, assim, desejar corrigir uma pretensa ideia da Ré relativamente aos conteúdos por ela desenvolvidos no desenrolar do processo. Para garantir a força de sua negação, recorre a intensificadores. Parece, dessa forma, querer aprisionar o interlocutor, no caso o juiz, a uma única possibilidade de interpretação do caso: a negação total dos fatos enunciados pela Ré e a adesão aos conteúdos enunciados por ela, Autora.

Outra possibilidade de intensificação da negação, que surte efeito semelhante de aprisionar o interlocutor, consiste no emprego, associado aos advérbios de negação, de outras classes de palavras, como, por exemplo, um adjetivo que ocupa uma posição mais próxima do negativo numa escala entre positivo e negativo, como no caso que segue:

(11) O resultado ainda assim não foi positivo, o que leva a (sic) conclusão de que o sistema de tração do cartão não é operacional, e portanto não preenche as especificações mínimas necessárias para a produção industrial. (PROC. 1754/94:11 - Ré)

$\mathrm{O}$ adjetivo mínimas, numa escala de valores entre grande e pequeno, em que máximo ocupa o lugar extremo na escala positiva, ocupa o lugar oposto, ou seja, o extremo na escala negativa. Por isso, em (11), é usado como reforço eficaz para a negação. Com seu emprego que intensifica a negação temos a impressão de que o locutor nega duplamente o conteúdo e traz para seu discurso dois enunciadores, um que afirma, outro que nega. Ele se opõe ao primeiro e reafirma o ponto de vista do segundo, reforçando-o. Dessa perspectiva, podemos dizer que a negação reforçada é fundamentalmente polifônica.

Finalmente, cabe observar como a interrogação funciona como estratégia de manipulação que conduz à resposta negativa, quando não contém em si um valor negativo. $\mathrm{O}$ fato é que, deixando a negação subentendida na pergunta, o locutor não se compromete com ela, mas aprisiona o interlocutor, impondo-lhe como certo um conteúdo negativo pressuposto pela pergunta e pelo seu contexto. Os exemplos apresentados a seguir constituem perguntas postas pela Ré ao perito.

(12) Presentemente, logrou a Ré tornar operacional o projeto? Em caso negativo, que dificuldades técnicas não foram ainda superadas? (PROC. 1754/94:25 Ré)

(13) O total de 100 (cem) horas programado para a assimilação dos conhecimentos técnico, entre reuniões com técnicos e explicações de conceitos funcionais do mecanismo, eram suficientes? Quantas horas de instruções foram efetivamente disponibilizadas? (PROC. 1754/94:25 - Ré)

(14) Existe na área objeto da inicial qualquer prova induvidosa do exercício da posse por parte do autor? (PROC. 1754/94:40 - Ré)

Em (12) e (13) a Ré, por meio de perguntas, seguidas, no primeiro exemplo, de uma resposta negativa e, no segundo, de uma outra pergunta que implica a resposta negativa relativamente à que a antecede, orienta a continuidade do discurso para respostas negativas; essa é sua intenção perante o perito.

Em (12), a segunda pergunta pressupõe que ainda há dificuldades a serem superadas e esse conteúdo permite atribuir à primeira pergunta, o valor de negação. É como se a parte afirmasse: Presentemente, não logrou a Ré tornar operacional o projeto. Na verdade, a Ré, ao recorrer à pergunta, traz para o seu discurso um enunciador com quem se alinha, cujo ponto de vista é o da negação, mas admite a presença de outro enunciador a quem se opõe, cujo ponto de vista é afirmativo.

Em (13), o modalizador efetivamente, presente na segunda pergunta, que complementa a antecedente, deixa implícito que as horas disponibilizadas pela Autora não foram suficientes. Entretanto, a Ré não tem autoridade para negar a suficiência das horas disponibilizadas; somente o perito pode fazê-lo. Assim sendo, a Ré procura induzir o perito à resposta negativa trazendo para sua pergunta um enunciador cujo ponto de vista é o de que o número de horas efetivamente disponibilizadas pela Autora não corresponde às cem previstas no contrato. O ponto de vista da Ré se alinha com esse enunciador.

Em (14), o pronome indefinido com valor negativo qualquer e o adjetivo induvidosa fornecem as pistas ao perito de que se espera dele um reposta negativa a esse quesito. Aliás, é como se a resposta "allait de soit"; como se a resposta negativa fosse uma verdade admitida já (cf. ANSCOMBRE et DUCROT, 1997).

É relevante observar a importância do contexto para a interpretação de uma pergunta com valor negativo. Nos dois primeiros excertos analisados, por exemplo, é a pressuposição de um discurso anterior com valor negativo contida nos enunciados que seguem às perguntas que lhes confere tal valor. Isoladamente, essas perguntas não poderiam ser interpretadas como uma negação, mas apenas como uma simples pergunta destinada a suprir uma lacuna de conhecimento. Entretanto, o contexto acaba por impor a continuidade do discurso, orientando-o argumentativamente. 


\section{Considerações finais}

Neste artigo, tratamos da negação como estratégia para marcar um tomada de posição das partes em um Processo Civil, posicionamento este fundado na alusão a um discurso contrário, ora contrapondo-se ao ponto de vista de um enunciador, ora refutando o dizer efetivo do interlocutor, ora afirmando um conteúdo negativo. Em todos esses casos, a negação serviu como estratégia argumentativa fundada na presença de outros, em polifonia, pois.

Com efeito, o Processo Civil insere-se numa área do Direito marcada pelo princípio do contraditório, isto é, pelo antagonismo de interesses que existe entre as partes, contexto em que a argumentação se constrói pela controvérsia, motivo pelo qual o emprego de negações apresenta-se como uma ferramenta fundamental para a atividade do profissional dessa área, isto é, para o discurso daquele cujo objetivo é contrapor-se ao adversário. A negação, como marca do antagonismo, atende a uma questão crucial para as partes: negar o discurso do outro, para fazer o juiz aceitar como verdadeiro o seu, admitindo que este é o detentor do direito.

A situação de enunciação dos autos impõe aos participantes que assumam posições claras, e, ao mesmo tempo, procurem prever, por oposição, os pontos de vista dos demais interlocutores, especialmente daquele se opõe à parte que detém o discurso, a fim de, ao contemplar a possibilidade de um discurso contrário ao seu, construir sua enunciação em oposição a tais pontos de vista que vão de encontro à sua pretensão. Trata-se de "uma situação de argumentação típica, na qual o domínio epistêmico e o domínio avaliativo, muitas vezes, se sobrepõem" (CABRAL, 2014, p. 72). Essa dinâmica, conforme pudemos observar nos excertos analisados, é marcada seja pela alusão a enunciadores a cujos pontos de vista as partes se opõem, seja pela presença de interlocutores, a quem também se deseja contradizer. Esse jogo que contempla locutores e/ou enunciadores detentores de pontos de vista antagônicos põe em evidência a negação como marca de polifonia e de intersubjetividade.

Este breve estudo nos permite concluir que, do ponto de vista argumentativo, embora negação descritiva e negação metalinguística constituam estratégias pertinentes, a negação polêmica se mostra mais produtiva para as partes. Ela parece também atender aos princípios que regem a própria dinâmica dos autos e, simultaneamente, atender aos preceitos da ética profissional, na medida em que, aludindo a um enunciador que assimila à parte contrária, sem fazer efetiva referência ao opositor, evita o confronto direto que poderia ser avaliado como excessivamente agressivo.

\section{Referências}

AMOSSY, Ruth. Apologie de la polémique. Paris: PUF, 2014.

AMOSSY, Ruth. De l'apport d'une distinction: dialogisme vs polyphonie dans l'analyse argumentative. BRES, Jacques; HAILLET, Patrick Pierre; MELLET, Sylvie; NØlke, Henning, ROSIER, Laurence (Dir.). Dialogisme et polyphonie approches linguistiques Actes du colloque de CERISY. Bruxelles: De Boeck \& Larcier, 2005.

ANSCOMBRE, Jean-Claude; DUCROT, Oswald. L'argumentation dans la langue. Liège: Mardaga, 1997.

BENVENISTE, Émile. Problèmes de linguistique générale1. Paris: Gallimard, 1966.

BENVENISTE, Émile. Problèmes de Linguistique Générale 2. Paris: Gallimard, 1974.

CABRAL, Ana Lúcia Tinoco. Enunciação e Argumentação no Discurso Jurídico: léxico, significação e sentido. In: OLIVEIRA, Esther Gomes de; SILVA, Suzete (org.). Semântica e Estilísica: dimensões atuais do Significado e do Estilo. Homenagem a Nilce Santa'anna Martins. Campinas: Pontes Editores, 2014, p. 57-73.

CABRAL, Ana Lúcia Tinoco. Enunciação e escrita acadêmica na área jurídica: subjetividade, intersubjetividade e argumentação. In: SPARANO, Magalí; VARGAS, Maria Valíria A. M. Enunciação, subjetividade e práticas de linguagem: revisitando Benveniste. São Paulo: Paulistana, 2011. p. 92-110.

CABRAL, Ana Lúcia Tinoco. A Interação Verbal em Processos Civis: um caso de trílogo. In: GIL, B. D.; AQUINO, Z. G. O. Anais do II Simpósio Internacional de Análise Crítica do Discurso e VIII Encontro Nacional de Interação em Linguagem Verbal e Não Verbal. Faculdade de Filosofia, Letras e Ciências Humanas, USP, 2007. Disponível em: <http://www.fflch.usp. br/dlcv/enil/pdf/76_Ana_Lucia_TC.pdf $>$. Acesso em: 08 ago. 2015.

DUCROT, Oswald. Provar e dizer: linguagem e lógica. São Paulo: Global, 1981.

DUCROT, Oswald. Le dire et le dit. Paris: Minuit, 1984.

GRECO FILHO, Vicente. Direito Processual Civil Brasileiro. São Paulo: Saraiva, 1995. v. 1.

GRECO FILHO, Vicente. Direito Processual Civil Brasileiro. São Paulo: Saraiva, 1996. v. 2.

GUIMARÃES, Deocleciano Torrieri. (org.). Dicionário técnico jurídico. São Paulo: Rideel, [s/d.].

HOUAISS, Antônio; VILAR, Mauro de Salles. Dicionário Houaiss da Língua Portuguesa. Rio de Janeiro: Objetiva, 2001.

KERBRAT-ORECCHIONI, Catherine. L'énonciation. Paris: Armand Colin, [1980] 1997.

MATEUS, M. H. M. et all. Gramática da língua portuguesa. 4. ed. Lisboa: Caminho, [1989] 1994.

MEYER, Michel. Principia Rhetorica une théorie générale de l'argumentation. Millau, France: Fayard, 2008.

NEGRÃO, Theotonio. A linguagem do advogado. In: Revista de Processo, São Paulo: Editora Revista dos Tribunais, v 13, n. 49, p. 83-90, jan.-mar. 1988. 
NEGRONI, María Marta García; COLADO, Marta Tordesillas. La enunciación en la lengua de la deixis a la polifonia. Madrid: Gredos, 2001.

PERES, João Andrade. Negação. In: RAPOSO, Eduardo Buzglo Paiva et al. Gramática do Português volume I. Lisboa: Fundação Calouste Gulbnkian, 2013.
SANTOS, Moacyr Amaral dos. Primeiras linhas de direito processual civil: Adaptadas ao novo Código de Processo Civil. São Paulo: Saraiva, 1977.

Recebido: 15 de agosto de 2015.

Aprovado: 25 de novembro de 2015.

Contato: altinococabral@gmail.com 